\title{
LOGÍSTICA LEAN COMO DIFERENCIAL COMPETITIVO PARA O SETOR METALÚRGICO
}

Flávio Belli ${ }^{1}$

\begin{abstract}
RESUMO
Este artigo teve como objetivo fazer uma revisão teórica sobre logística lean e analisar os impactos que esta filosofia pode gerar na logística quando aplicada no setor metalúrgico da cidade de Joinville. A metodologia da pesquisa se caracteriza como de natureza básica em relação ao tema abordado. Quanto aos seus procedimentos técnicos, enquadra-se como um estudo bibliográfico, pois tratou de dados e verificações provindas diretamente de trabalhos já realizados do assunto pesquisado. Do ponto de vista dos objetivos, classifica-se como exploratória e descritiva. Quanto aos resultados obtidos neste trabalho, destaca-se, a proposta de conceito de logística lean com foco no atendimento do cliente e a visibilidade dos desperdícios que existe na logística do setor metalúrgico e que oportuniza um direcionamento para a busca da eficiência global. Neste sentido, este estudo permitiu identificar as oportunidades de melhoria que a logística pode obter através da utilização da filosofia lean e mostrou que o setor metalúrgico pode se beneficiar com a utilização de ferramentas lean.
\end{abstract}

Palavras-chave: Melhoria contínua. Logística. Filosofia lean.

${ }^{1}$ Especialista, e-mail: flavio.belli@sc.senai.br/flavio.belli@tigre.com 


\section{INTRODUÇÃO}

Os mercados consumidores estão em constante mutação e suas necessidades se alteram numa velocidade cada dia mais rápida, neste sentido as organizações necessitam de uma sintonia cada vez maior com os seus processos internos para dar uma reposta a esta demanda no mesmo ritmo que Ihe é solicitado, por isto a filosofia lean está sendo aplicada na manufatura (LIMA; ZAWISLAK, 2003).

O desafio atual é atender a necessidade do mercado consumidor que exige cada vez mais das empresas agilidade, eficiência e agregação de valor, e com estes direcionadores as organizações buscam alterar os processos, independente do seu ramo de atuação, para ser globalmente competitiva, (ELIZABETH; CASSANDRA, 2011; CUDNEY; ELROD, 2010).

Neste contexto, um dos motivadores que impulsionam e desafiam a organização a buscar uma mudança brusca no gerenciamento das suas operações é a necessidade de alinhamento dos objetivos estratégicos, táticos e operacionais com a execução das atividades. Esta mudança de visão promove uma reavaliação dos processos internos e força a busca pela melhoria contínua, que é sustentada pela aplicação da filosofia lean e exige uma revisão dos fluxos de materiais e fluxos de informação, (SÁNCHEZ; PEREZ, 2001).

Desta forma a filosofia Lean esta sendo adaptada na logística permitindo uma visão mais precisa dos conceitos de valor, fluxos de valor, fluxo de produtos, sistema puxado (JONES et al., 1997 apud WU, 2003; SÁNCHEZ; PEREZ, 2001).

A filosofia lean quando implantada na logística proporciona uma evolução na excelência operacional e permite que as organizações atendam as exigências do mercado no que se refere à qualidade na prestação de serviço como um diferencial competitivo (FLEURY; LAVALLE, 1995). Esta diretriz promove uma revisão dos processos logísticos através de análise do sistema logístico e serve de ponto de partida para a incorporação da filosofia lean no processo de melhoria contínua. Algumas indústrias, como por exemplo, na automotiva, em seu processo de reorganização foram influenciadas pela filosofia de organização da produção: a manufatura enxuta - ME ME (LIMA; ZAWISLAK, 2003).

A estratégia para adaptar os conceitos da manufatura enxuta na logística lean deve considerar as diferenças que os processos possuem e eleger as ferramentas que melhor atendem as suas necessidades, pois, em sua essência, a logística já tem um apelo enxuto, devido o seu foco na redução dos custos e na eficiência (FIGUEIREDO, 2006; KERR, 2006).

Segundo Christopher (1997, p.2):

a logística é o processo de gerenciar estrategicamente a aquisição, movimentação e armazenagem de materiais, peças, produtos acabados (e os fluxos de informações correlatas) através da organização de seus canais de marketing, de modo a poder maximizar a lucratividade presente e futura através do atendimento dos pedidos a baixo custo. 
Neste sentido, este trabalho teve como objetivo fazer uma revisão teórica sobre logística lean e analisar os impactos que esta filosofia pode gerar na logística quando aplicada no setor metalúrgico da cidade de Joinville. Para atingir o objetivo proposto, utilizouse como procedimento técnico a pesquisa bibliográfica. A coleta de dados da pesquisa bibliográfica foi realizada por meio das bases de dados ISI, Wiley, Scopus e Google acadêmico. As palavras-chave utilizadas foram: lean logistics, lean chain, lean supplier, lean supply chain, lean supply chains, lean supply chain management. O resultado parcial da busca simples é composto por 1615 publicações que foram encontradas.

Posteriormente, as publicações foram selecionadas tendo como critério o alinhamento do título ao tema em foco no presente trabalho. Desta forma, uma segunda amostra parcial foi selecionada, com um total de 68 publicações que foram lidas e reclassificadas. Chegou-se a uma amostra final composta por 25 artigos. Já como o direcionamento de aplicabilidade desta pesquisa, foi proposta um modelo de mapeamento dos pontos críticos e das fontes de desperdícios que o setor metalúrgico de Joinville possui, seguido de uma sugestão de técnicas lean que a literatura aponta como essências para a logística.

Neste contexto, torna-se imprescindível conhecer as responsabilidades da logística numa organização, assuntos abordados na seção 2. Em seguida, na seção 3, é realizada uma revisão dos processos logísticos na logística lean. Já, na seção 4 apresenta-se uma proposta de conceito de logística lean. Na sequência, na seção 5 , relata a situação do setor metalúrgico do ponto de vista da classificação dos desperdícios e mapeamento da logística lean, seguido pelas conclusões e oportunidades de pesquisa na seção 6 .

\section{RESPONSABILIDADE DA LOGÍSTICA NUMA ORGANIZAÇÃO}

As organizações estão num processo de mudança constante para se adequarem as necessidades do mercado que exige flexibilidade, agilidade e um excelente nível de serviço, e neste sentido a logística contribui estrategicamente, pois as suas atividades interferem no fluxo da informação, fluxo material e fluxo financeiro (ELIZABETH; CASSANDRA, 2011; CUDNEY; ELROD, 2010).

De acordo com Lima e Zawislak (2003) Lean é uma filosofia denominada produção enxuta e ou modelo de produção da Toyota, com foco na redução dos desperdícios e que promove a melhoria contínua através de jornadas lean. Também utiliza técnicas e princípios para eliminar os problemas encontrados nos processos, produtivos e administrativos (kaizen, MFV etc.).

Neste sentido a logística esta adaptando a filosofia lean para facilitar a visualização dos fluxos, pois através da ferramenta MFV (Mapa de fluxo de valor) é possível desenhar o fluxo de valor e as atividades que não agregam valor (KERR, 2006; WEE; WU, 2009; OLIVEIRA; ARAÚJO, 2009). 
O trabalho de análise dos fluxos deve começar depois que a organização definir as atividades de responsabilidade da logística para facilitar o direcionamento e entendimento das oportunidades de melhoria, pois isto é crucial para o sucesso do processo de implantação da filosofia lean (KONECKAS, 2010). A falta de definição clara das responsabilidades faz com que as tenham dificuldades durante a implementação de processo enxutos (MASKELL, 1999, apud NOGUEIRA; CASALINHO, 2008).

No sentido de facilitar a definição das atividades logísticas foi relacionado no quadro 1 o processo de evolução das atividades ao longo dos períodos.

Quadro 1: Evolução das atividades logísticas

\begin{tabular}{|c|c|c|}
\hline Era & Período & Descrição \\
\hline $\begin{array}{l}\text { 1) Da fazenda } \\
\text { ao mercado }\end{array}$ & $\begin{array}{l}\text { Período anterior às } \\
\text { guerras mundiais }\end{array}$ & $\begin{array}{l}\text { Foco das atividades era simplesmente no transporte } \\
\text { e armazenagem. }\end{array}$ \\
\hline $\begin{array}{l}\text { 2) Funções } \\
\text { Segmentadas }\end{array}$ & $\begin{array}{l}\text { Até o fim da } \\
\text { década de } 50 .\end{array}$ & $\begin{array}{l}\text { Aparecem as atividades logísticas, mas elas ainda } \\
\text { são vistas como funções diferentes dentro da } \\
\text { organização. A influência militar começa a ser mais } \\
\text { profunda, levando a desenvolvimentos da engenharia } \\
\text { com foco na logística. }\end{array}$ \\
\hline $\begin{array}{l}\text { 3) Funções } \\
\text { Integradas }\end{array}$ & Início dos anos 60. & $\begin{array}{l}\text { Abordagem mais sistêmica da logística e o conceito } \\
\text { de custo total se popularizam. Existe um objetivo de } \\
\text { integração das atividades logística, mesmo que ainda } \\
\text { de uma forma interna. }\end{array}$ \\
\hline $\begin{array}{l}\text { 4) Foco no } \\
\text { Consumidor }\end{array}$ & Nos anos 70 & $\begin{array}{l}\text { A idéia de serviço ao consumidor passou a ser um } \\
\text { ponto de debate importante, com o aumento da } \\
\text { influência do Marketing. }\end{array}$ \\
\hline $\begin{array}{l}\text { 5) Logística } \\
\text { como fator de } \\
\text { diferenciação }\end{array}$ & $\begin{array}{l}\text { No início dos anos } \\
80\end{array}$ & $\begin{array}{l}\text { A logística passou a ser vista como um fator de } \\
\text { diferenciação na empresa. Nesse sentido, a visão } \\
\text { estratégica da logística passou a ter peso dentro da } \\
\text { firma. Conceitos como cadeia de suprimentos, canais } \\
\text { de distribuição, eficiência e tecnologia de informação } \\
\text { ganharam destaque. }\end{array}$ \\
\hline $\begin{array}{l}\text { 6) Expansão } \\
\text { de Fronteiras }\end{array}$ & $\begin{array}{l}\text { Essa era diz } \\
\text { respeito à metade } \\
\text { da década de } 90 \\
\text { até os dias atuais. }\end{array}$ & $\begin{array}{l}\text { A percepção do cliente e seu comportamento diante } \\
\text { do sistema logístico passaram a ser levados em } \\
\text { consideração. Surgem as redes logísticas, logística } \\
\text { internacional e atividades multifuncionais. }\end{array}$ \\
\hline
\end{tabular}

Fonte: Adaptado de Kent e Flint ( 1997 apud VIEIRA; RODRIGUEZ, 2011) 
Neste contexto as organizações definem como atribuições de responsabilidade da logística segundo Christopher (2007), suprimentos, armazenagem, gerenciamento dos estoques, movimentação interna, distribuição, transporte e etc. A execução das atividades logística deve ter como foco o atendimento do cliente no tempo certo, com qualidade e com um custo justo (SÁNCHEZ; PÉREZ, 2001; KOBAYASHI, 2000).

\section{DEFINIÇÃO DE PROCESSOS LOGÍSTICOS NA LOGÍSTICA LEAN}

A necessidade de gerenciar os processos logísticos da organização não está focada apenas nas atividades internas, mas sim, ultrapassou a fronteira da organização, agregando entre os direcionadores de tomadas de decisões, os fornecedores e os clientes (SGARBI JUNIOR; CARDOSO, 2011; WU, 2003).

Neste contexto os processos logísticos na logística lean devem buscar eliminar os desperdícios em atividades que não agreguem valor ao cliente que permitem a organização reduzir os seus custos totais (ZHOU et al., 2008).

O foco da logística lean deve estar concentrado nos três grandes processos logísticos (logística de abastecimento, logística interna e logística de distribuição). Nestes processos demonstrados através da figura 1 a logística lean deve buscar a melhoria contínua aplicando a técnica do kaizen e a ferramenta do MFV, para identificar os gaps (lacuna) nas interfaces e redesenhar o fluxo, reduzindo as fontes de desperdícios e de não agregação de valor (WEE; WU, 2009; IMAI, 2005).

Figura 1: Fluxo de Materiais

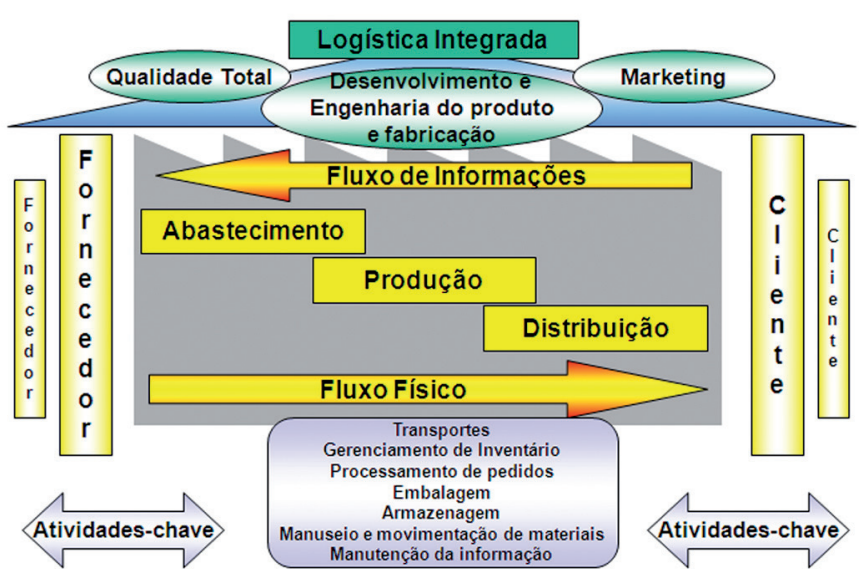

Fonte: Pires; Musetti (2000) 
Os processos logísticos na logística lean evoluem conforme a necessidade do cliente, porém sua área de atuação deve estar concentrada nas atividades que agreguem valor e na redução das atividades que não agreguem valor (PHELPS; SMITH; HOENES, 2003; ZYLSTRA, 2008).

\section{PROPOSTA DE CONCEITO DE LOGÍSTICA LEAN}

A logística lean é um sistema puxado com reposição em pequenos lotes, definido entre as empresas e plantas ao longo do fluxo de valor. Além disso, a logística lean necessita de um sinal para a puxada (EDI, Kanban, WEB, etc.), e também precisa de dispositivos de nivelamento nas etapas do fluxo de valor, um modelo de entrega freqüente em pequenos lotes, que pode ser vários cross-dock para a consolidação de cargas nos loops de reposição (LÉXICO LEAN, 2007).

Neste contexto a logística lean direciona suas ações ao fluxo de valor e foca nas etapas que agregam valor ao produto e que o cliente percebe (ZYLSTRA, 2008). O conceito de logística lean esta em construção e o processo iniciou com a pesquisa de alguns autores como (NAYLOR; NAIM; BERRY, 1999; BOISSON, 2008; KERR, 2006; FERRO, 2006). Neste sentido foi elaborado o quadro 2 que contém uma coletânea de conceitos de logística e suas variações na visão dos autores.

Quadro 2: Análise dos conceitos de logística, logística lean e logística lean agile

\begin{tabular}{|c|c|c|c|}
\hline Autor e Ano & Conceito de Logística & $\begin{array}{l}\text { Conceito de Logística } \\
\text { Lean }\end{array}$ & $\begin{array}{l}\text { Conceito de } \\
\text { Logística Lean Agile }\end{array}$ \\
\hline $\begin{array}{l}\text { NAYLOR;NAIM; } \\
\text { BERRY, } 1999 . \\
\text { KONECKAS, } 2010 .\end{array}$ & & $\begin{array}{l}\text { - Alto foco na redução } \\
\text { do lead time, na } \\
\text { redução do custo e } \\
\text { melhoria da qualidade; } \\
\text { Baixo foco na } \\
\text { prestação de serviço. }\end{array}$ & $\begin{array}{l}\text { Alto foco na } \\
\text { redução do lead } \\
\text { time, melhoria } \\
\text { da qualidade e } \\
\text { da prestação de } \\
\text { serviço; } \\
\text { Baixo foco na } \\
\text { redução do custo. }\end{array}$ \\
\hline
\end{tabular}




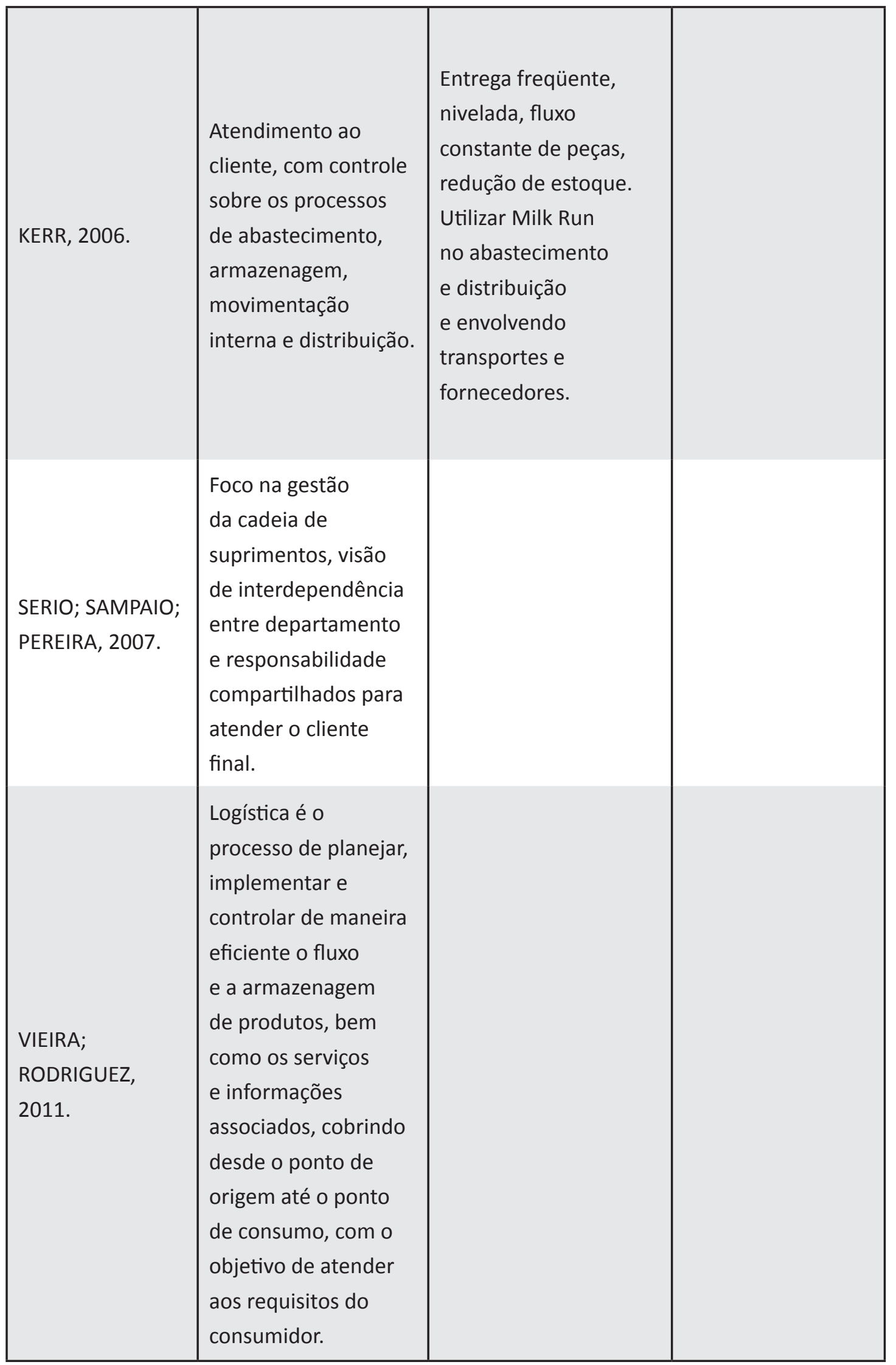




\begin{tabular}{|c|c|c|c|}
\hline FERRO, 2006 & & $\begin{array}{l}\text { A premissa } \\
\text { fundamental é } \\
\text { considerar os custos } \\
\text { totais, que envolve } \\
\text { o transporte e a } \\
\text { movimentação, } \\
\text { além de considerar } \\
\text { estocagem, perdas de } \\
\text { vendas, ou multas pelo } \\
\text { não cumprimento dos } \\
\text { prazos de entrega e } \\
\text { outros custos invisíveis. }\end{array}$ & \\
\hline $\begin{array}{l}\text { CHRISTOPHER } \\
1997 \text { apud } \\
\text { BOISSON, } 2008\end{array}$ & $\begin{array}{l}\text { Logística é o processo } \\
\text { de gerenciar } \\
\text { estrategicamente } \\
\text { a aquisição, } \\
\text { movimentação e } \\
\text { armazenagem de } \\
\text { materiais, peças e } \\
\text { produtos acabados, } \\
\text { controlando o fluxo } \\
\text { físico e de informação } \\
\text { de modo a maximizar } \\
\text { a lucratividade } \\
\text { presente e } \\
\text { futuras através do } \\
\text { atendimento dos } \\
\text { pedidos com baixo } \\
\text { custo. }\end{array}$ & $\begin{array}{l} \\
\text { Logística lean, visa } \\
\text { criar valor ao cliente } \\
\text { mediante um serviço } \\
\text { logístico com o menor } \\
\text { custo total. }\end{array}$ & \\
\hline
\end{tabular}

Fonte: Do autor (2012)

A definição dos conceitos de logística lean que foi apresentado por Ferro (2006) e Boisson (2008) são os que mais se aproximam da realidade brasileira, pois a logística no Brasil ainda está num processo de formalização e de busca pela independência. 


\section{SITUAÇÃO DO SETOR METARLÚRGICO DE JOINVILLE}

O setor metalúrgico de Joinville possui uma relação de dependência com as montadoras de veículos. Os altos e baixos deste segmento após a crise de 2008 vem provocando muita instabilidade. Os impactos desta instabilidade são a demissão de funcionários, a necessidade de reestruturação, os prejuízos decorrentes de cancelamento de pedidos e o baixo giro dos estoques. Neste contexto a logística têm um papel estratégico para o setor metalúrgico de Joinville, pois os custos decorrentes da logística inbound (logística de abastecimento), logística interna e logística outbound (logística de disribuição) são consideráveis devido às características destes materiais que possuem uma alta densidade, o que acarreta um custo significativo na movimentação.

Neste sentindo, o grande desafio para o setor metalúrgico, é saber como identificar os desperdícios na logística e criar uma sinergia entre as empresas da região de Joinville, com foco na busca da melhor eficiência dos processos logísticos.

Quadro 3: Análise dos sete desperdícios

\begin{tabular}{|c|c|c|}
\hline $\begin{array}{l}\text { Sete } \\
\text { Desperdícios }\end{array}$ & Problema & Valor \\
\hline Superprodução & $\begin{array}{l}\text { Atividades executadas além da } \\
\text { necessidade. }\end{array}$ & $\begin{array}{l}\text { Altos custos com estoques } \\
\text { desnecessários e risco de } \\
\text { perdas dos estoques, etc. }\end{array}$ \\
\hline Transporte & $\begin{array}{l}\text { Má utilização da capacidade dos } \\
\text { veículos, falta de planejamento das } \\
\text { rotas etc. }\end{array}$ & Altos custos com fretes. \\
\hline Estoque & $\begin{array}{l}\text { Baixa acurrácidade da previsão, gera } \\
\text { desbalanceamento dos estoques, baixo } \\
\text { giro dos estoques etc. }\end{array}$ & $\begin{array}{l}\text { Altos custos com estoques } \\
\text { desnecessários e risco de } \\
\text { perdas dos estoques, etc. }\end{array}$ \\
\hline Espera & $\begin{array}{l}\text { Veículos aguardando carga e descarga, } \\
\text { parada de linhas de produção etc. }\end{array}$ & $\begin{array}{l}\text { Impacto nos custos de fretes, } \\
\text { custos transformação de } \\
\text { produtos, etc. }\end{array}$ \\
\hline Processamento & $\begin{array}{l}\text { Complexidade na preparação do pedido } \\
\text { e faturamento, etc. }\end{array}$ & $\begin{array}{l}\text { Impacto nos custos de fretes, } \\
\text { custos transformação de } \\
\text { produtos, etc. }\end{array}$ \\
\hline
\end{tabular}




\begin{tabular}{|l|l|l|}
\hline \multirow{2}{*}{ Movimento } & $\begin{array}{l}\text { O Fluxo de materiais e produtos } \\
\text { acabado confuso na entrada, } \\
\text { internamente e saída das fábricas até a } \\
\text { estocagem no armazém. }\end{array}$ & $\begin{array}{l}\text { Impacto nos custos de fretes, } \\
\text { custos transformação de } \\
\text { produtos, etc. }\end{array}$ \\
Defeitos & $\begin{array}{l}\text { Avarias nos produtos, devido o excesso } \\
\text { de movimentações. }\end{array}$ & Impacto no custo logístico. \\
\hline
\end{tabular}

Fonte: Do autor (2012)

A visibilidade que os sete desperdícios apresentados no quadro 3 trazem para as organizações é estratégica e pode ser uma oportunidade de rever o papel da logística dentro do setor metalúrgico, pois permite que ela se reorganize e busque um diferencial competitivo. A busca pelo diferencial competitivo começa pelo alinhamento entre os objetivos estratégicos e o foco na identificação das oportunidades de melhoria.

Neste contexto a inclusão da filosofia lean na logística é crucial e determinante, pois a utilização de técnicas como o MFV, Heijunka, kaizen entre outras, provoca um repensar constantes dos processos logísticos e promove a melhoria contínua.

\subsection{Mapeamento da logística com a inclusão da fislosofia lean}

O processo de mudança da logística com a inclusão das técnicas lean inicia com o mapeamento dos processos do estado atual e estado futuro. Através do mapeamento do estado atual as empresas do setor metalúrgico irão visualizar os desperdícios e as oportunidades de melhoria, o próximo passo é desenhar o mapa do estado futuro. Uma das técnicas lean utilizadas para desenhar estes mapas é o kaizen. A vantagem de se utilizar o kaizen é o foco e a escolha das pessoas chaves de cada área envolvida.

Neste contexto a logística lean visa as atividades que aditam valor e não agregação de valor para traçar um plano de ação que favoreçam a organização. A falta de conhecimento dos fluxos logísticos internos e externos é outro problema que o mapa do estado atual soluciona. 
Figura 2: Mapa de fluxo de valor do estado atual da área de logística de movimentação de produtos acabados entre os armazéns de distribuição

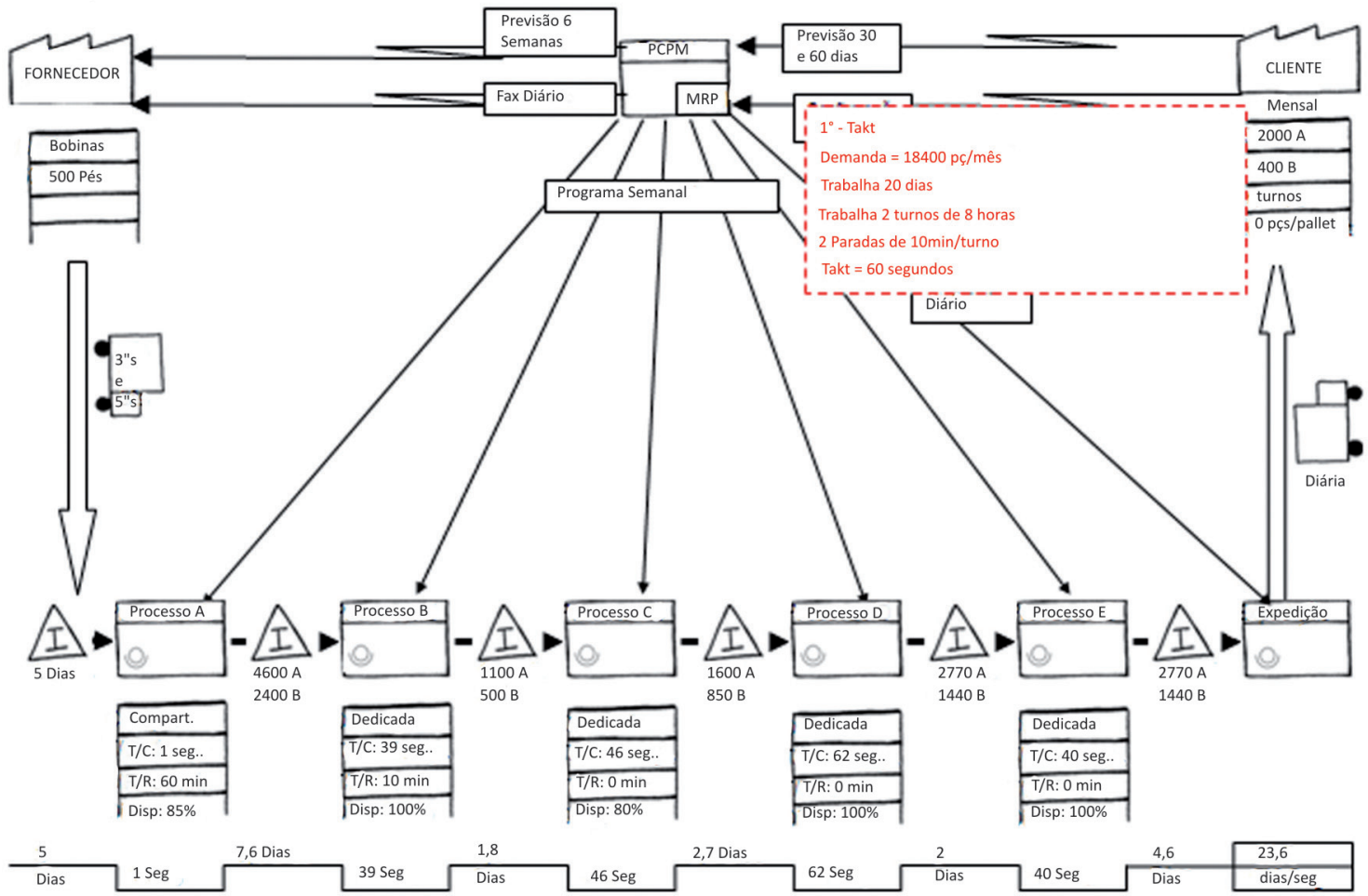

Fonte: Do autor (2012)

No exemplo do mapa de fluxo de valor (MFV) do estado atual que foi ilustrado através da figura 2, pode-se, perceber como o processo funciona e que numa visão tradicional não seria possível enxergar o fluxo como um todo. Também observa-se como o excesso de estoque entre estas atividades, as constantes esperas, as movimentações desnecessárias e as superproduções, podem aumentar os custos logísticos.

No processo de elaboração do MFV do estado futuro, deve ser sustentado pelo MFV do estado atual para evitar que os desperdícios identificados permanecem no MFV do estado futuro. Outro segredo para o sucesso para esta atividade é utilizar as técnicas lean na construção do MFV do estado futuro, dentre elas as mais recomendas são, heijunka, kanban, nivelamento e balanceamento da produção, sistema puxado de produtos acabados, eliminando estoque em vários pontos do fluxo, também foi utilizado FIFO, padronização, definição de rotas de movimentação, layout produtivo e supermercado. A figura 3 é um exemplo ilustrativo que serve como orientação no processo de construção do MFV do estado futuro. 
Figura 3: Mapa de fluxo de valor do estado futuro da área de logística de movimentação de produtos acabados entre os armazéns de distribuição

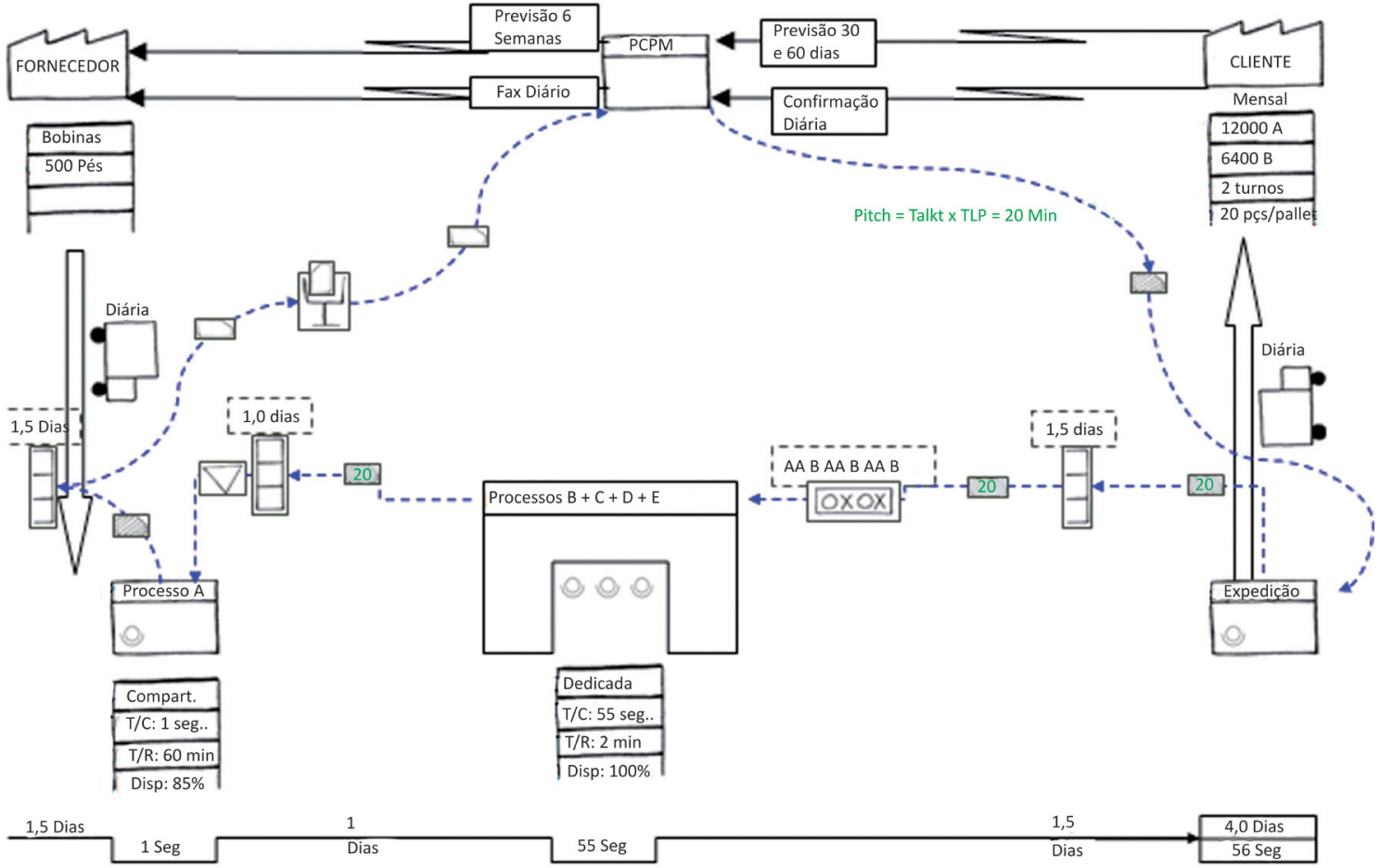

Fonte: Do autor (2012)

A construção de mapas como estes, pode ajudar as organizações do setor metalúrgico de Joinville a conhecer a sua logística e facilitar na construção dos planos de ações para as melhorias necessárias para torná-las competitivas.

\section{CONCLUSÕES}

No levantamento bibliográfico realizado, observou-se que ainda é difícil definir o conceito de logística lean. Alguns autores listam alguns modelos a serem aplicados na implantação da logística lean e que podem vir a ser o conceito, outros apenas mencionam alguns estágios de preparação para a implantação da filosofia lean na logística, outros citam a filosofia lean , porém com enfoque na adaptação da Manufatura Enxuta.

Por outro lado, na análise do setor metalúrgico de Joinville, foi constatadas oportunidades de melhoria e que implantação filosofia lean na logística, promove uma redução nos custos logísticos através da redução dos desperdícios e das atividades que não agreguem valor. Neste contexto, a inclusão das técnicas lean nos processos logísticos permitirá as organizações deste setor oportunizar conhecimento, padronização e repasse informações aos geradores de desperdícios. 
Conclui-se que, mesmo com o conceito de logística lean ainda em construção, o setor metalúrgico de Joinville pode aplicar as técnicas já testadas e pesquisadas nas melhorias dos processos logísticos e na eliminação dos seus desperdícios com foco na redução das atividades que não agreguem valor.

A logística lean envolve a redução de desperdícios por todos os processos logísticos, seu foco está concentrado nas atividades que agregam valor aos clientes internos e externos, e a sua sustentabilidade depende da estratégia de busca pela melhoria contínua e pela competitividade. Portanto, não existem processos logísticos sem desperdícios (estoques, movimentações, etc.), neste sentido o conceito de logística lean deve focar nas interfaces que possuem características baseadas na necessidade de melhoria contínua.

\title{
LEAN LOGISTICS AS COMPETITIVE DIFFERENTIAL FOR METALLURGICAL INDUSTRY
}

\begin{abstract}
The objective of this article was to do a theoretical review about Lean logistics and analyze the impacts that this philosophy can produce on logistics when applied in the metallurgical sector of the city of Joinville. The research methodology is characterized as basic in nature in relation to the addressed issue. As for his technical procedures, classifies itself as a bibliographic review, because considered data and findings coming directly from works already done on the researched subject. From the viewpoint of the objectives, it is classified as exploratory and descriptive. As for the results obtained in this work, the article illustrate the proposed concept of Lean logistics focusing on customer service and visibility of wastes that exist in the logistics of the metallurgic sector and that offers a guidance to the pursuit of overall efficiency. This study allowed identifying opportunities for improvement that the logistics can obtain through the use of the Lean philosophy and showed that the metallurgical sector can benefit from the use of Lean tools.
\end{abstract}

Keywords: Continuous improvement. Logistics. Lean philosophy. 


\section{REFERÊNCIAS}

BOISSON, Priscila de Andrade Ramos. Logística Lean: conceituação e aplicação em uma empresa de cosméticos. 2008. TESE (Doutorado) - Pontifícia Universidade Católica do Rio de Janeiro - PUC RIO, Rio de Janeiro, 2008

CHRISTOPHER, Martin. Logística e gerenciamento da cadeia de suprimentos. São Paulo: Pioneira, 1997.

Logística e gerenciamento da cadeia de suprimentos. 2.ed. São Paulo: Thonsom Pioneira, 2007.

CUDNEY, E.; ELROD, C. Incorporating lean concepts into supply chain management. International Journal of Six Sigma and Competitive Advantage, v.6, n. 1-2, p. 12-30, 2010.

ELIZABETH, C.; CASSANDRA, E. A comparative analysis of integrating lean concepts into supply chain management in manufacturing and service industries. International Journal of Lean Six Sigma, v. 2, n. 1, p. 5-22, 2011.

FERRO, J. R. Lean mail: Logística Lean, passo seguinte na transformação. out 2006. Disponível em: <http://www.lean.org.br/leanmail/mailOutubro06.htm> Acesso em: 25 mar. 2012.

FIGUEIREDO, Kleber. A Logística enxuta. Rio de Janeiro: Centro de estudos em logística do COPPEAD/UFRJ, 2006.

FLEURY, Paulo F.; LAVALLE, C. R. O estágio de desenvolvimento da organização logística em empresas brasileiras: estudo de casos. In: ENANPAD, 19., 1995, Rio de Janeiro, Anais... Rio de Janeiro: Instituto de Pós-Graduação e Pesquisa em Administração, COPPEAD/ UFRJ, 1995.

IMAI, M. Kaizen a estratégia para o sucesso competitivo. 6. ed. São Paulo: Instituto IMAM, 2005.

KERR, J. Lean production perfectly synchronizes demand and replenishment. But it's not just about manufacturing. Here's how lean thinking applies to logistics. Logistics Management. May 1, 2006.

KOBAYASHI, Shun'ichi. Renovação da logística: como definir as estratégias de distribuição física global. São Paulo: Atlas, 2000.

KONECKAS. Lean and agile supply chain management concept in the aspect of risk management. LogForum, v. 6., 4.ed., n. 3, 2010.

LÉXICO LEAN. Glossário ilustrado para praticantes do Pensamento Lean. São Paulo, SP: Lean Institute Brasil, 2007. 
LIMA, M. L. S. C.; ZAWISLAK, P. A. A produção enxuta como fator diferencial na capacidade de fornecimento de PMEs/ Lean production as a tool to improve the supply capability of the SMEs. Produção, [S.I], v. 13, n. 2, p. 57-69, 2003.

NAYLOR, J. B.; NAIM, M. M.; BERRY, D.B.. Leagility: Integrating the lean and agile manufacturing paradigms in the total supply chain. Int. J. Production Economics, [S.I], 62, pp.107-118, 1999.

NOGUEIRA, M. G. S; CASALINHO, G. D. O. Proposta de uma matriz de indicadores para avaliação de práticas enxutas. In: Encontro Nacional de Engenharia de Produção: A INTEGRAÇÃO DE CADEIAS PRODUTIVAS COM A ABORDAGEM DA MANUFATURA SUSTENTÁVEL, 28., 2008, Rio de Janeiro. Anais... Rio de Janeiro, RJ, Universidade Federal do Rio Grande do Sul, 2008.

OLIVEIRA, R. O; ARAÚJO, R. B. Otimizando os processos logísticos pela implantação do OTIF com Lean Seis Sigma. Tecnol. Metal. Mater., São Paulo, v. 5, n. 4, p. 235-240, abr./ jun. 2009.

PHELPS, T. SMITH, M. HOENES, T. Developing Lean Supply Chains: a Guidebook. Michigan: Altarum Institute, 2003.

PIRES, Sílvio R. I.; MUSETTI, Marcel A. Fábrica do Futuro: entenda hoje como sua indústria vai ser amanhã. Banas, São Paulo, cap.7, p.65-76, dez. 2000.

SÁNCHEZ, M. A.; PÉREZ, M. P. Lean indicators and manufacturing strategies. International Journal of Operations \& Production Management, [S.I], vol.21, no.11, pp.1433-1451, 2001.

SERIO, Luiz Carlos D.; SAMPAIO, Mauro; PEREIRA, Susana Carla Farias. A Evolução dos Conceitos de Logística: um Estudo na Cadeia Automobilística no Brasil. Rev. de Administração e Inovação, [S.I], v. 4, n. 1, 2007.

SGARBI JUNIOR, Guilherme; CARDOSO, Álvaro Azevedo. Lean Seis Sigma na Logística: aplicação a Gestão dos Estoques em uma Empresa de Autopeças. In: ENCONTRO NACIONAL DE ENGENHARIA DE PRODUCAO: INOVAÇÃO TECNOLÓGICA E PROPRIEDADE INTELECTUAL: DESAFIOS DA ENGENHARIA DE PRODUÇÃO NA CONSOLIDAÇÃO DO BRASIL NO CENÁRIO ECONÔMICO MUNDIAL, 31., 2011, Belo Horizonte, MG, Anais... Belo Horizonte: ABEPRO - ENEGEP, 2011.

VIEIRA, Carolina L. dos Santos; RODRIGUEZ, Carlos Manuel Taboada. Uma Perspectiva sobre o Desenvolvimento do Conceito de Logística. In: ENCONTRO NACIONAL DE ENGENHARIA DE PRODUCAO: INOVAÇÃO TECNOLÓGICA E PROPRIEDADE INTELECTUAL: DESAFIOS DA ENGENHARIA DE PRODUÇÃO NA CONSOLIDAÇÃO DO BRASIL NO CENÁRIO ECONÔMICO MUNDIAL, 31., 2011, Belo Horizonte, MG, Anais... Belo Horizonte: ABEPRO - ENEGEP, 2011. 
WEE, H. M.; WU, S. Lean supply chain and its effect on product cost and quality: A case study on Ford Motor Company. Supply Chain Management, [S.I], vol. 14, no. 5, pp. 335341, 2009.

WU, Yen Chun. Lean manufacturing: a perspective of lean suppliers. International Journal of Operations \& Production Management, [S.I], vol. 23, no. 11, pp.1349 - 1376, 2003.

ZHOU, G. et al. Evaluating the comparative efficiency of Chinese third-party logistics providers using data envelopment analysis. International Journal of Physical Distribution \& Logistics Management, [S.I], vol. 38, no. 4, pp. 262-279, 2008.

ZYLSTRA, K. D.. Distribuição Lean: a abordagem enxuta aplicada à distribuição, logística e cadeia de suprimentos. Porto Alegre: Bookman, 2008.

\section{SOBRE O AUTOR}

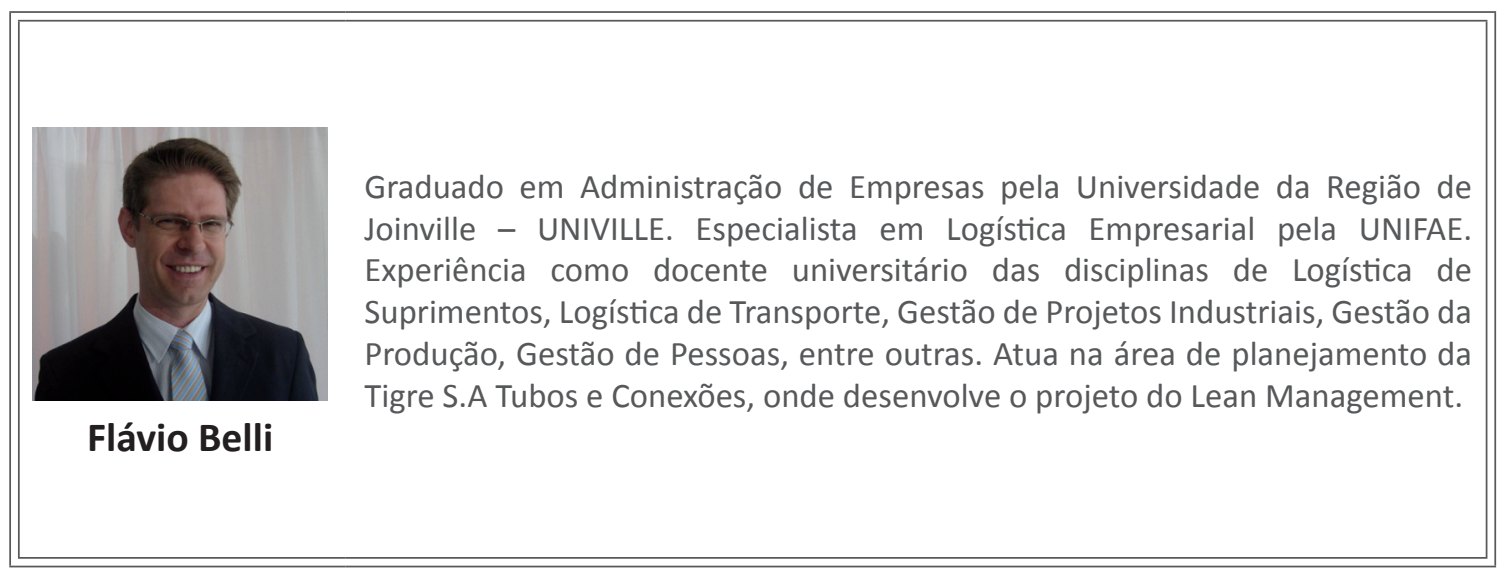

